\title{
Deprivation and food access and balance in Saskatoon, Saskatchewan
}

\section{J. Cushon, PhD (1); T. Creighton, MSc-GISc (1); T. Kershaw, MPH (1); J. Marko, MPH (1); T. Markham, BSHEc (2)}

This article has been peer reviewed.

\begin{abstract}
Introduction: We explored food access and balance in Saskatoon, Saskatchewan, Canada in relation to material and social deprivation.

Methods: We mapped the location of all large supermarkets and fast food retailers in Saskatoon. Supermarket accessibility index scores and food balance scores were compared to material and social deprivation indexes to determine significant associations.
\end{abstract}

Results: Our results indicate that the poorest access to supermarkets occurred in areas west of the South Saskatchewan River and also in suburban areas around the perimeter of the city. Areas west of the river are some of the most deprived areas in the city. Saskatoon's mean food balance ratio of 2.3 indicates that access favours fast food. However, we did not find a clear pattern or clear socio-economic gradient for most measures.

Conclusion: This study highlights the importance of contextual studies of food access. This study also highlighted a number of other issues that should be explored in the Saskatoon context such as individual-level food consumption patterns, mobility, temporal dimensions of food access and economic access as well as interventions that could improve food access in the city.

Keywords: food access, health, deprivation, socio-economic status

\section{Introduction}

Access to healthy, nutritious food is associated with health outcomes at an ecological level. ${ }^{1-4}$ As a result, there is increasing interest in exploring such access within specific geographic areas, and particularly whether disparities in access exist based on factors such as socio-economic status (SES).

\section{Food access and health}

Food access is typically measured in terms of spatial proximity to types of food outlets. $^{5}$ Large supermarkets tend to provide a greater variety of healthy foods at lower prices than do smaller grocery stores or convenience stores. ${ }^{6-13}$ Studies show that, compared with those who live further away, residents who live close to supermarkets are more likely to eat larger quantities of fruit and vegetables and have overall healthier diets and lower levels of obesity. ${ }^{6,14-19}$

On the other hand, fast food outlets tend to sell nutritionally deficient, processed foods that are high in calories and sodium. ${ }^{20}$ Some studies have found that living close to fast food outlets is associated with lower quality diets, obesity and adverse health outcomes such as diabetes and heart disease. ${ }^{6,16,21-24}$ However, other studies have not found an association between proximity to fast food outlets and dietary and health outcomes. ${ }^{25-27}$

\section{Food balance and health}

Food balance is the ratio of the proximity of supermarkets (and hence access to healthy foods) to that of fast food outlets (and access to unhealthy foods). Food balance has been found to correlate with health outcomes. ${ }^{28,29}$ For example, a study in Edmonton, Alberta, found that food balance was significantly associated with obesity, and the more "imbalanced" an area, the more likely that a resident would be obese. ${ }^{29}$

\section{Food access and socio-economic status}

Diet socio-economic gradient, where groups at higher SES consume healthier diets than those living at lower SES, exist internationally as well as in Canada. ${ }^{30}$ One of the explanations for the diet socioeconomic gradient is access: residents of deprived areas have less access to healthy foods compared with residents of more affluent areas. ${ }^{31}$ For low-income residents, access to a vehicle is sometimes limited, which compounds issues of food access. ${ }^{13,24,32}$ A mixed methods study conducted in Saskatoon, Saskatchewan, found that the main issues that affected food-buying practices were owning a vehicle, income and convenience. ${ }^{33}$

American studies have found that access to healthier foods is generally worse in

1. Public Health Observatory, Population and Public Health, Saskatoon Health Region, Saskatoon, Saskatchewan, Canada 2. Health Promotion Department, Population and Public Health, Saskatoon Health Region, Saskatoon, Saskatchewan, Canada 
deprived areas. ${ }^{21,34}$ However, empirical studies from other developed countries have produced mixed results. Studies carried out in Canada, Australia and Scotland have been inconclusive, with some even finding that low-income neighborhoods had better access to healthy foods compared with more affluent neighborhoods. $8,12,20,35$

\section{Food deserts}

Food access research in the past decade has increasingly focused on food deserts. Food deserts are defined by the United States Department of Agriculture as "a low-income census tract where a substantial number or share of residents has low access to a supermarket or large grocery store."36
Whereas research from the United States has found strong support for the existence of food deserts, in Canada findings on food deserts have been less conclusive. ${ }^{34}$ In fact, a study from Montreal, Quebec, found very few food deserts; conversely, low-income residents had better access to supermarkets than did other residents. ${ }^{7}$ Another study determined that low-income residents in Edmonton, Alberta, had better access to supermarkets, on average; ${ }^{10}$ however, the lowest-income residents were also 2.3 times more likely to have a fast food restaurant within a 5- to 10-minute walk compared with those in more affluent neighbourhoods, ${ }^{37}$ findings similar to those from the United States. ${ }^{38-40}$ A study in London, Ontario, showed that certain low-income neighborhoods were food deserts, although more affluent areas also had poor access to supermarkets. ${ }^{41}$ This suggests that food access research is required on a case-bycase basis to inform local policy and practice. $^{31,34}$

In this study, we aim to address the following research questions:

(1) How do food access and balance in Saskatoon vary according to arealevel deprivation?

(2) Does food access and balance follow a socio-economic gradient in Saskatoon?

\section{Methods}

\section{Food retailers and fast food outlets}

We defined supermarkets as retail grocery outlets that belong to major chains

FIGURE 1

Material deprivation in Saskatoon, Saskatchewan

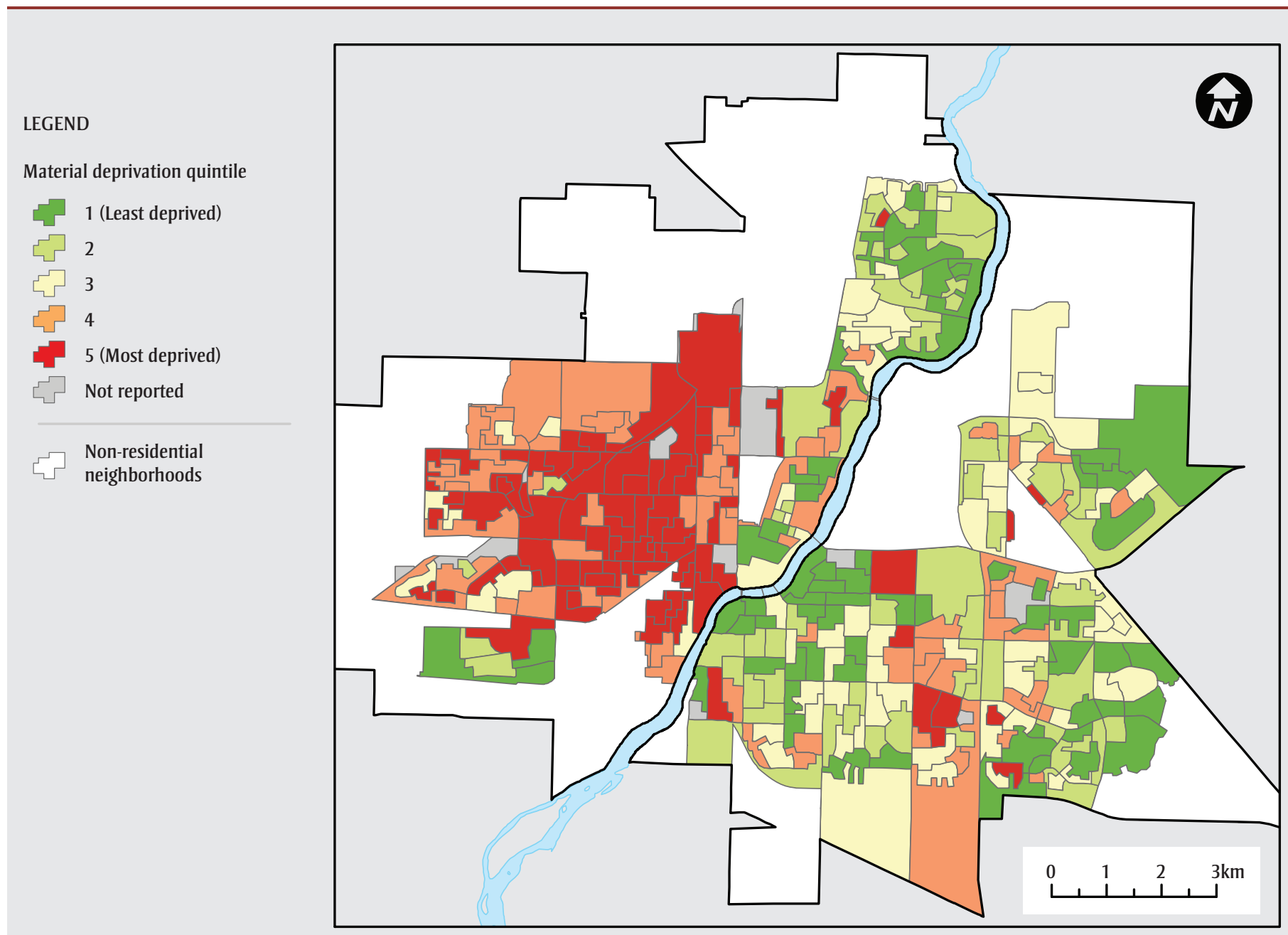


FIGURE 2

Social deprivation in Saskatoon, Saskatchewan

LEGEND

Social deprivation quintile

1 (Least deprived)

2

ᄃ〕 3

ᄃ 4

5 (Most deprived)

Not reported

Non-residential neighborhoods

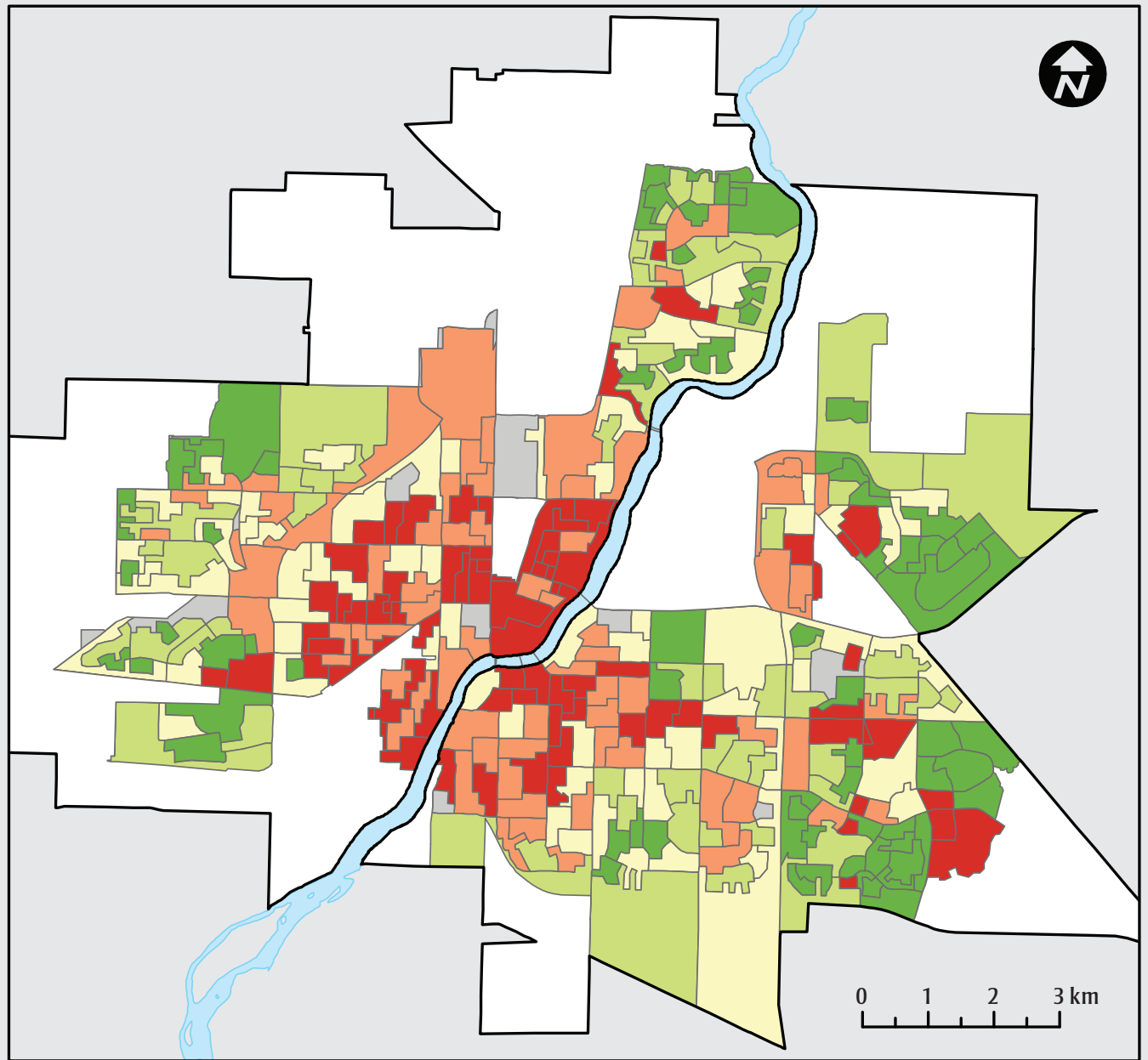

because these tend to consistently offer a greater variety of healthy products at more affordable prices than do smaller and independent supermarkets or other food retailers (e.g. Walmart stores in Saskatoon did not offer many food options at the time of this study). ${ }^{7,42}$ To find the locations of all the supermarkets in Saskatoon, representing access to healthy food $(n=22)$, we used several data sources from 2007 and 2008, including the phone book, company websites and local information. Locations were verified with a Global Position System (GPS) unit, Google Earth and address points from the City of Saskatoon. All locations were geocoded in a database.
We defined fast food outlets as those restaurants where there are no wait staff and patrons pay for their food before receiving it and then themselves carry it to a table or out of the outlet. ${ }^{43}$ We located all fast food outlets, food courts in malls and convenience stores that served hot food ( $n=120$ ) using data supplied by the Safe Communities Department, Saskatoon Health Region in August 2008. Locations were then geocoded in the same fashion as were supermarket locations.

\section{Deprivation}

We determined area-level deprivation using the deprivation index developed by the Institut national de santé publique du Québec (INSPQ). ${ }^{44}$ This index measures deprivation at the level of dissemination areas (DAs), the smallest areas for which the Canada Census data are available. ${ }^{45}$ DAs are made up of 1 or more neighbouring blocks that include approximately 400 to 700 residents. The deprivation index includes 2 dimensions, social and material. Social deprivation is composed of 3 variables: proportion of lone parents, proportion of residents living alone and marital status. Material deprivation is measured using the following variables: educational attainment, average income and employment status. For this study, the INSPQ provided us with Saskatoon DA 
scores according to both material and social deprivation. The DA scores were calculated based on the 2006 Canadian Census. We assigned DAs to deprivation quintiles, each of which represented approximately $20 \%$ of Saskatoon's population. Figures 1 and 2 depict material and social deprivation in Saskatoon. Note that the South Saskatchewan River that runs through Saskatoon demarcates the east and west sides of the city.

\section{Food access and balance}

Based on the methodology used by Apparicio et al. ${ }^{7}$ in Montreal, Quebec, we used 3 measures to determine supermarket access: proximity, diversity and variety. These were all calculated at the block level. We calculated proximity by measuring the
Euclidean (i.e. straight-line) distance between the centroid (i.e. geographic centre) of each city block and each supermarket. Diversity was defined as the mean number of supermarkets within 1 kilometre (i.e. walking distance ${ }^{7}$ ) of the centroid of each block. Variety was defined as the mean distance from each block's centroid to the 3 nearest supermarkets from different chains. Residents with a number of different chains all within close proximity have the greatest choice of brands and prices. ${ }^{7}$

We combined the proximity, diversity and variety measures to create an accessibility index for supermarkets, a novel approach to measuring food accessibility. Proximity scores were classified into tertiles based on all of the scores at the block level. If a block fell into the worst tertile for proxi- mity, it was given a score of 1 ; otherwise, it was given a score of 0 . Variety scores were also classified into tertiles, and the blocks were scored in the same manner as for proximity. For the diversity measure, an additional score of 1 was added if a block had no supermarkets within a kilometre. The scores for each block were added together to produce an index score, with a maximum score of 3 indicating blocks with the worst accessibility to supermarkets.

Dividing the minimum distance to a supermarket by the minimum distance to a fast food outlet generated a food balance score for each block. A food balance score of 1 indicated that fast food outlets and supermarkets were the same distance from a block's centroid. Areas with a food

FIGURE 3

Proximity to nearest supermarket, Saskatoon, Saskatchewan

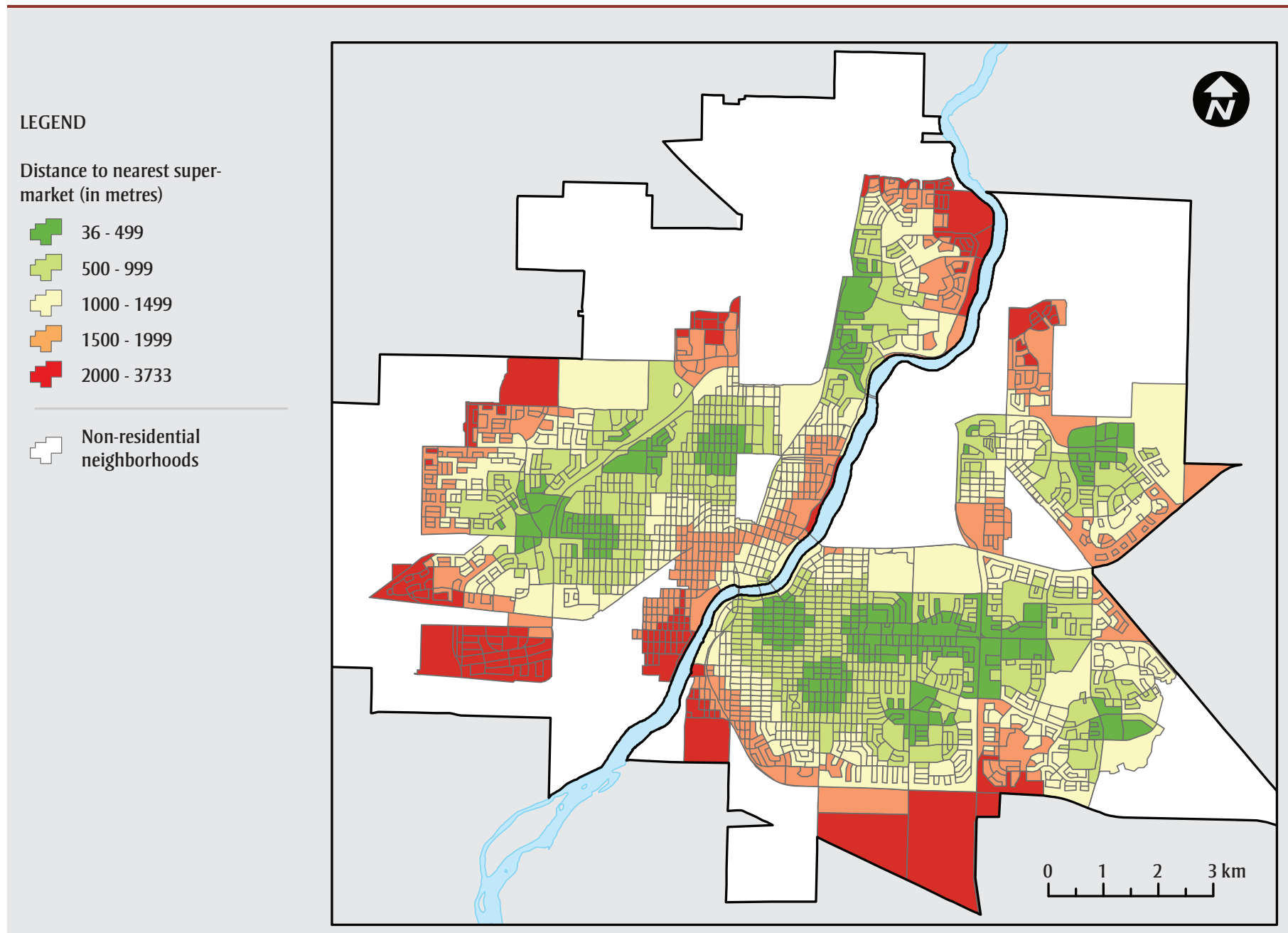


TABLE 1

Descriptive statistics for food access and food balance by 2006 material deprivation quintile, Saskatoon, Saskatchewan

\begin{tabular}{|c|c|c|c|c|c|}
\hline & \multicolumn{5}{|c|}{ Quintile } \\
\hline & 1 (least deprived) & 2 & 3 & 4 & 5 (most deprived) \\
\hline Total population, n & 39353 & 39418 & 39536 & 39528 & 39144 \\
\hline $\begin{array}{l}\text { Supermarket proximity }{ }^{\mathrm{a}} \\
\text { mean (SD) distance, m }\end{array}$ & $993(530)$ & $1086(541)$ & 1085 (607) & 1097 (564) & 1141 (559) \\
\hline $\begin{array}{l}\text { Population within } 1000 \mathrm{~m} \text { of } \\
\text { supermarket, \% }\end{array}$ & 49 & 48 & 38 & 33 & 54 \\
\hline $\begin{array}{l}\text { Supermarket diversity }{ }^{\mathrm{b}} \text {, mean } \\
\text { (SD) }\end{array}$ & 0.97 (1.08) & $0.69(0.92)$ & $0.90(1.23)$ & $0.85(1.30)$ & $0.65(0.84)$ \\
\hline $\begin{array}{l}\text { Supermarket variety, mean } \\
\text { (SD) distance, m }\end{array}$ & $1580(596)$ & 1767 (606) & 1625 (679) & $1620(590)$ & $1647(563)$ \\
\hline $\begin{array}{l}\text { Fast food proximity }{ }^{\mathrm{a}} \text {, mean } \\
\text { (SD) distance, } \mathrm{m}\end{array}$ & 737 (465) & $802(486)$ & 762 (586) & $680(418)$ & $642(401)$ \\
\hline $\begin{array}{l}\text { Population within } 1000 \mathrm{~m} \text { of } \\
\text { fast food outlet, } \%\end{array}$ & 70 & 78 & 67 & 71 & 84 \\
\hline $\begin{array}{l}\text { Food balance score, mean } \\
\text { (SD) }\end{array}$ & $2.0(3.8)$ & $1.8(1.9)$ & $2.1(2.2)$ & $2.3(3.4)$ & $2.8(3.7)$ \\
\hline $\begin{array}{l}\text { Population with food balance } \\
\text { score }>2, \%\end{array}$ & 19 & 24 & 29 & 30 & 36 \\
\hline
\end{tabular}

Abbreviation: SD, standard deviation.

a Proximity is defined as the Euclidean (i.e. straight-line) distance between the centroid (geographic centre) of each city block and each supermarket.

${ }^{b}$ Diversity is defined as the mean number of supermarkets within 1 kilometre of the centroid of each block.

c Variety is defined as the mean distance from each block's centroid to the 3 nearest supermarkets from different chains.

TABLE 2

Descriptive statistics for food access and food balance by 2006 social deprivation quintile, Saskatoon, Saskatchewan

\begin{tabular}{|c|c|c|c|c|c|}
\hline & \multicolumn{5}{|c|}{ Quintile } \\
\hline & 1 (least deprived) & 2 & 3 & 4 & 5 (most deprived) \\
\hline Total population, n & 39572 & 39690 & 39612 & 39366 & 38739 \\
\hline $\begin{array}{l}\text { Supermarket proximity } \\
\text { mean }(\mathrm{SD}) \text { distance, } \mathrm{m}\end{array}$ & $1346(536)$ & $1145(629)$ & 978 (486) & $1065(527)$ & $972(575)$ \\
\hline $\begin{array}{l}\text { Population within } 1000 \mathrm{~m} \text { of } \\
\text { supermarket, } \%\end{array}$ & 24 & 37 & 48 & 54 & 59 \\
\hline $\begin{array}{l}\text { Supermarket diversity }{ }^{\mathrm{b}} \text {, mean } \\
\text { (SD) }\end{array}$ & $0.38(0.69)$ & $0.85(1.22)$ & $0.98(1.17)$ & $0.79(1.02)$ & $0.92(1.13)$ \\
\hline $\begin{array}{l}\text { Supermarket variety, mean } \\
\text { (SD) distance, m }\end{array}$ & $1916(570)$ & $1714(686)$ & $1452(515)$ & $1655(580)$ & $1588(617)$ \\
\hline $\begin{array}{l}\text { Fast food proximity }{ }^{\mathrm{a}} \text {, mean } \\
\text { (SD) distance, } \mathrm{m}\end{array}$ & $1072(612)$ & $781(510)$ & $641(316)$ & $628(380)$ & $604(443)$ \\
\hline $\begin{array}{l}\text { Population within } 1000 \mathrm{~m} \text { of } \\
\text { fast food, } \%\end{array}$ & 57 & 69 & 75 & 86 & 83 \\
\hline $\begin{array}{l}\text { Food balance score, mean } \\
\text { (SD) }\end{array}$ & $1.7(1.2)$ & $1.8(1.3)$ & $2.0(2.9)$ & $2.7(3.9)$ & $2.7(4.1)$ \\
\hline $\begin{array}{l}\text { Population with food balance } \\
\text { score }>2, \%\end{array}$ & 33 & 21 & 19 & 34 & 32 \\
\hline
\end{tabular}

Abbreviation: SD, standard deviation.

a Proximity is defined as the Euclidean (i.e. straight-line) distance between the centroid (geographic centre) of each city block and each supermarket.

${ }^{b}$ Diversity is defined as the mean number of supermarkets within 1 kilometre of the centroid of each block.

c Variety is defined as the mean distance from each block's centroid to the 3 nearest supermarkets from different chains. 
FIGURE 4

Diversity of supermarkets, Saskatoon, Saskatchewan

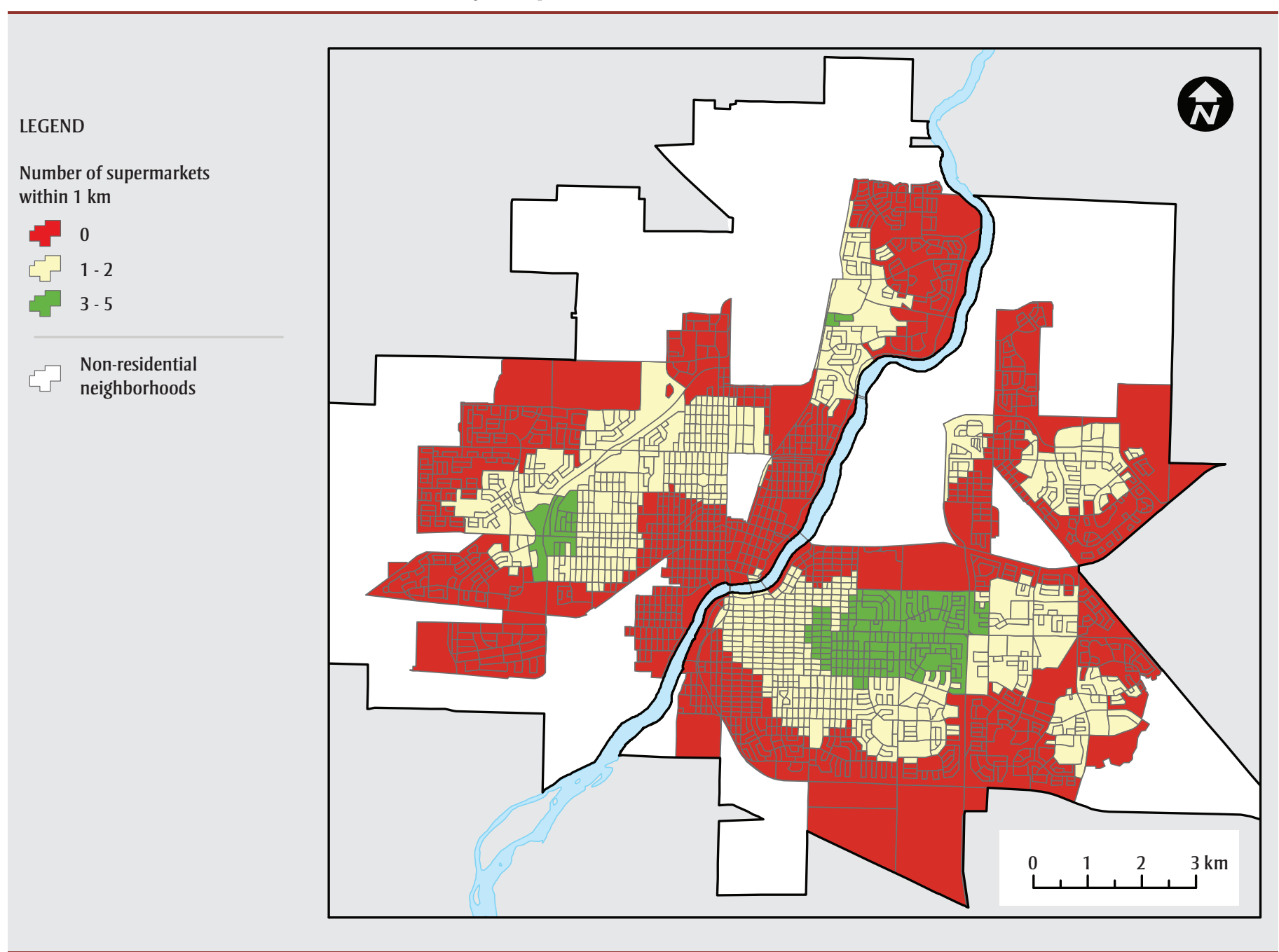

balance score of less than 1 , because the nearest supermarket was closer than the nearest fast food outlet, were considered more "balanced.",23

Finally, because our data were not normally distributed, we explored the associations between food access, food balance, material deprivation and social deprivation using Kruskal-Wallis nonparametric tests. We used post-hoc Mann-Whitney U tests with a Bonferroni correction to determine the existence of significant differences between deprivation quintiles.

We also sought to determine areas of concern in terms of food access and balance. Areas of concern were defined as deprived areas (i.e. areas that fell into quintile 5 for either material or social deprivation) with both poor accessibility to supermarkets (a score of 3 on the accessibility index) and a food balance score in favour of fast food outlets (a food balance score of 2 or more).

\section{Results}

\section{Supermarkets}

\section{Proximity}

Almost half (45\%) of the population lived within 1 kilometre of a supermarket. The mean distance of all residential blocks to the nearest supermarket was 1094 metres.
(See Figure 3; more detailed information available on request.)

Proximity differed significantly according to both material deprivation (see Table 1; more information available on request) and social deprivation (see Table 2; more information available on request). For example, for material deprivation, the most deprived blocks (quintile 5) were significantly further away from the nearest supermarket than the least deprived blocks (quintile 1). Proximity tended to decrease as deprivation increased.

However, for social deprivation we found that the least deprived blocks (quintile 1) were significantly further from the nearest supermarket than all other quintiles. 
Proximity tended to improve as deprivation increased, although it was very similar in both quintile 3 and quintile 5 blocks.

\section{Diversity}

The mean diversity number for Saskatoon was 0.79 , meaning that the average resident did not have any supermarkets within a walking distance of 1 kilometre (see Figure 4; more information available on request). Diversity was quite poor in many areas of the city, particularly in the materially and socially deprived areas west of the South Saskatchewan River and those around the perimeter of the city where deprivation was mixed (i.e. blocks in these areas fell into quintiles 1 through 5).
We also found that diversity differed significantly according to material deprivation (see Table 1; more information available on request) and social deprivation (see Table 2; more information available on request). Diversity tended to worsen as material deprivation increased, although quintile 2 blocks did not adhere to this pattern and blocks in quintiles 2 and 5 were both significantly worse in terms of supermarket diversity.

For social deprivation, the least deprived blocks (quintile 1) were significantly worse than all other quintiles.

\section{Variety}

The mean distance to the nearest 3 supermarkets from different chains (Figure 5) was 1657 metres. Similar to the proximity and diversity measures, variety was particularly poor in the more deprived areas west of the South Saskatchewan River and in the suburban areas on the edges of the city where deprivation was mixed.

Variety differed significantly according to both material deprivation and social deprivation. For material deprivation, quintile 2 blocks were significantly further from the nearest 3 supermarkets than quintile 1 blocks (see Table 1). A clear pattern for variety according to material deprivation did not emerge.

When variety is considered according to social deprivation, the least deprived blocks (quintile 1) were significantly

FIGURE 5

Variety of supermarkets, Saskatoon, Saskatchewan

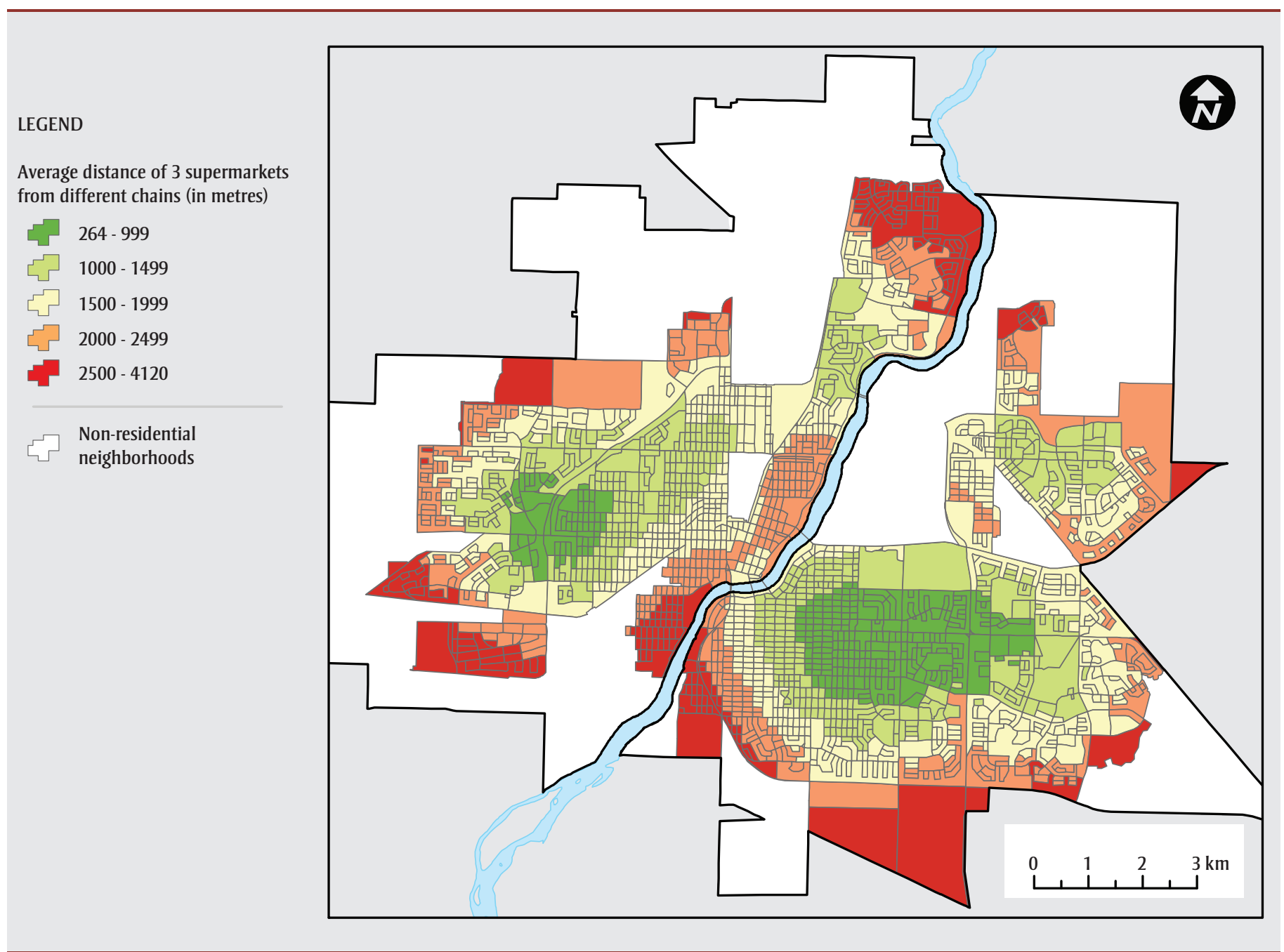


further from the nearest 3 supermarkets than all other quintile blocks (see Table 2). A clear pattern also did not exist for variety and social deprivation.

\section{Fast food}

\section{Proximity}

Three-quarters (74\%) of the city's population lived within 1 kilometre of a fast food outlet, and the mean distance to the nearest one was 724 metres (see Figure 6). Generally, blocks with the furthest proximity to fast food outlets were found on the perimeters of the city, where the deprivation was mixed.

Proximity to the nearest fast food outlet differed significantly by material deprivation, with the most deprived blocks (quintile 5) significantly closer to the nearest fast food outlets than the least deprived blocks (quintile 1). However, proximity to the nearest fast food outlet did not appear to follow a socio-economic gradient (see Table 1).

For social deprivation, the least deprived blocks (quintile 1) were significantly further from the nearest fast food outlet than all other quintile blocks (see Table 2). Proximity to the nearest fast food outlet tended to increase as social deprivation increased.

\section{Food balance}

The mean food balance ratio in Saskatoon was 2.3 , meaning the average resident lived more than twice as far from a supermarket as from a fast food retailer (see Figure 7). However, certain areas on the west side that were more materially and socially deprived had a food balance ratio as high as 58.8 .

Food balance differed significantly by material deprivation, with some of the most deprived blocks (quintiles 4 and 5) significantly more imbalanced than the least deprived (quintiles 1 and 2) (see Table 1). In general, food balance worsened as material deprivation increased.

Food balance also differed significantly by social deprivation (see Table 2), with blocks in quintiles 4 and 5 significantly more imbalanced than those in quintile 1

FIGURE 6

Proximity to fast food outlets, Saskatoon, Saskatchewan

\section{LEGEND}

Distance to nearest fast food outlet (in metres)

10 - 499

ᄃ $500-999$

־־ $1000-1499$

ᄃ匹 $1500-1999$

$2000-3496$

Non-residential neighborhoods

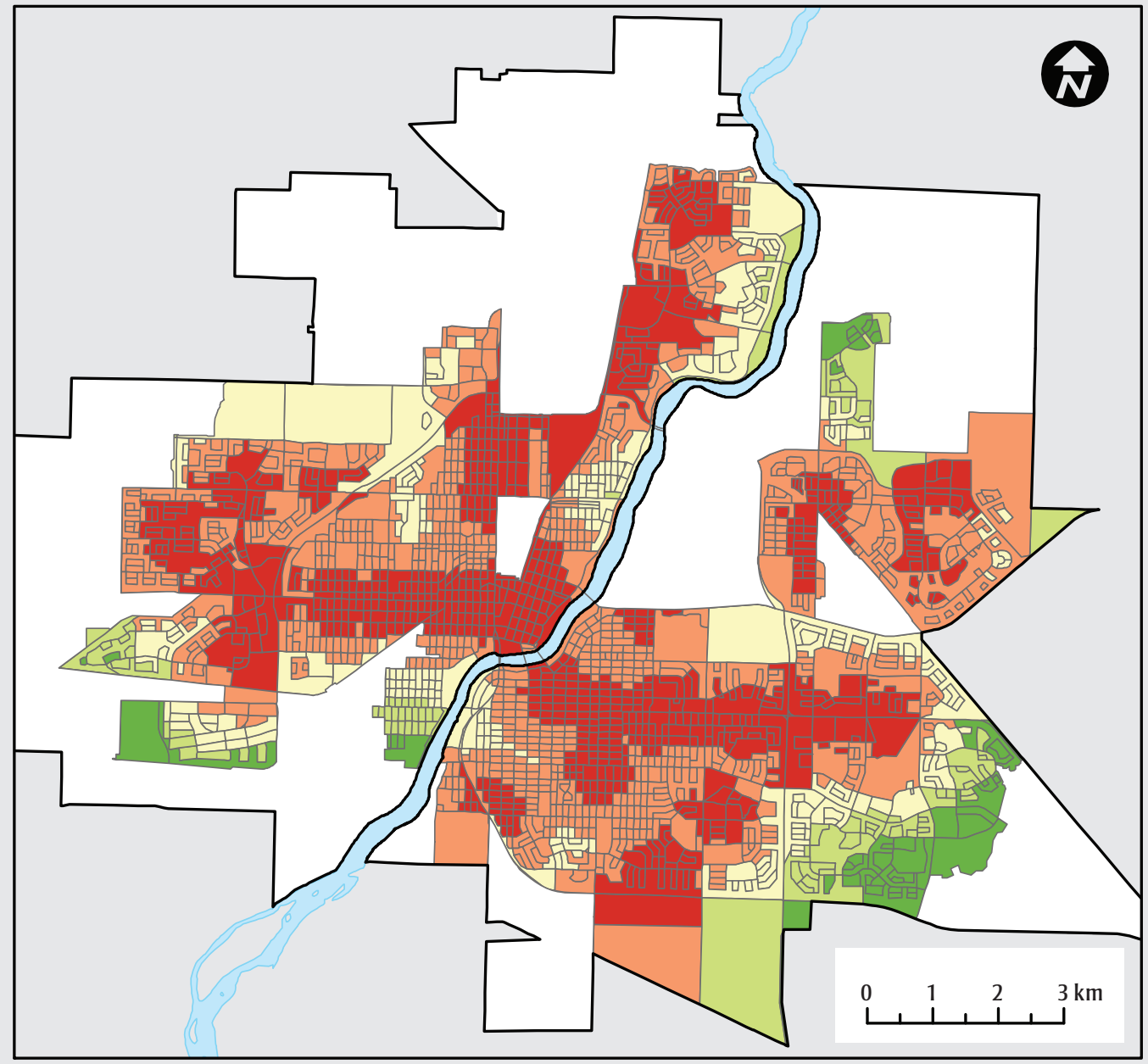


FIGURE 7

Food balance ratio, Saskatoon, Saskatchewan

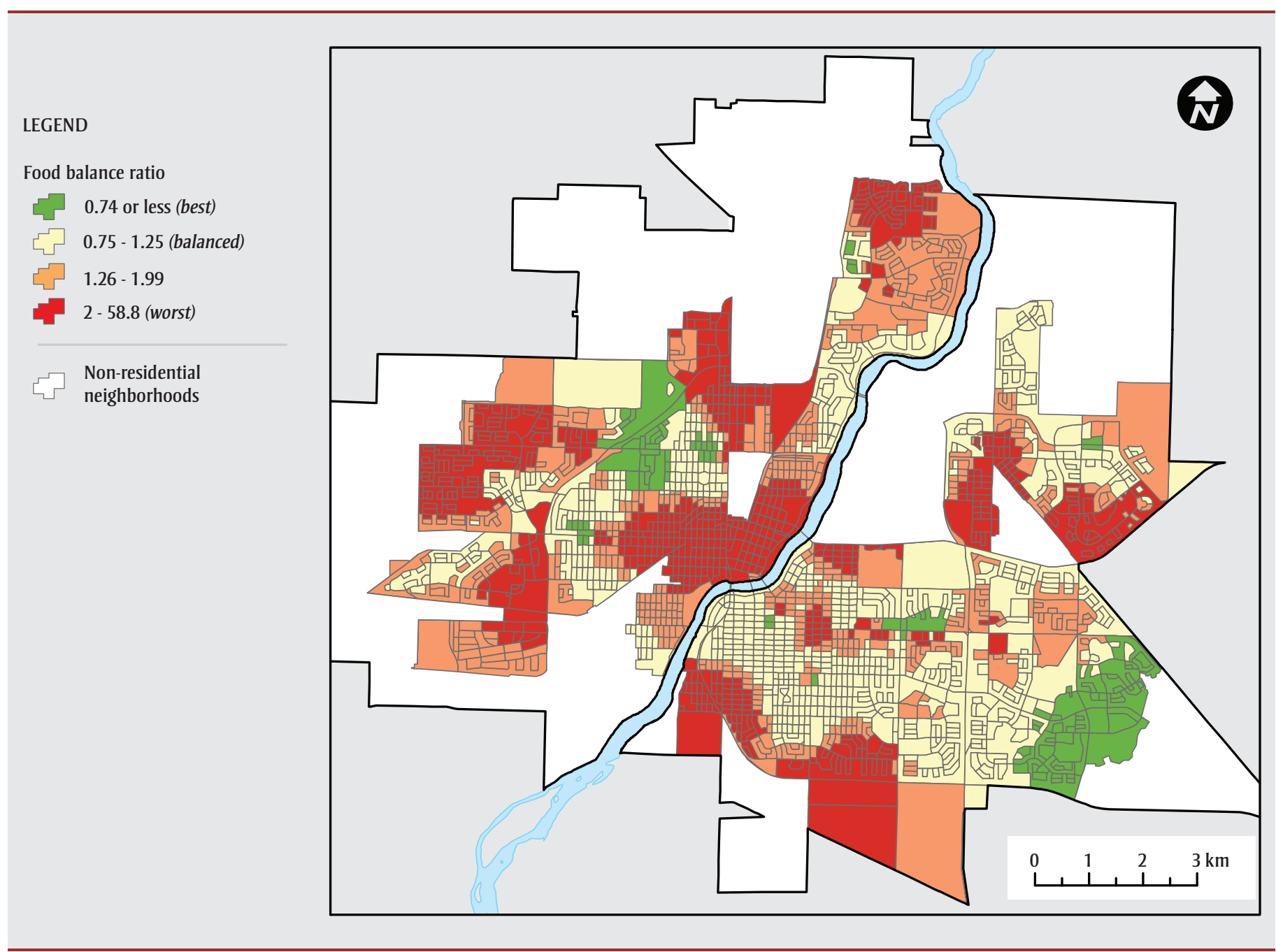

to 3. Food balance worsened as social deprivation increased.

\section{Areas of concern}

We combined food balance scores and accessibility index scores to identify areas of concern in the most materially or socially deprived (quintile 5) parts of Saskatoon. Figure 8 shows areas of concern according to material deprivation, while Figure 9 shows areas of concern according to social deprivation. According to material deprivation, Saskatoon's largest area of concern was located south of the city and on the west side of the South Saskatchewan River. When looking at social deprivation, the largest area of concern shifted slightly to the north.

\section{Discussion}

Our results indicate that access to supermarkets measured in terms of proximity, diversity and variety did not follow a clear pattern. Proximity tended to worsen as material deprivation increased but improved as social deprivation increased. Diversity also tended to worsen as material deprivation increased, although quintile 2 blocks did not conform to this pattern. Diversity according to social deprivation and variety according to either type of deprivation did not adhere to a clear pattern. Other Canadian studies investigating food access and area-level socio-economic status have also not found a clear pattern. ${ }^{7,10,12,41}$
Three-quarters of Saskatoon residents lived within walking distance (1 kilometre or less) of a fast food outlet, yet less than half lived within walking distance of a supermarket. This may have been due to the big difference between the number of supermarkets $(n=22)$ and the number of fast food outlets $(n=120)$ as assessed in the study; however, this still does not explain why certain more deprived areas on the west side had a food balance ratio as high as 58.8. Fast food proximity did not follow a pattern in terms of material deprivation although it generally increased as social deprivation increased. Food balance generally worsened as material deprivation and social deprivation increased. 
FIGURE 8

Materially deprived areas with poor supermarket accessibility and poor food balance, Saskatoon, Saskatchewan

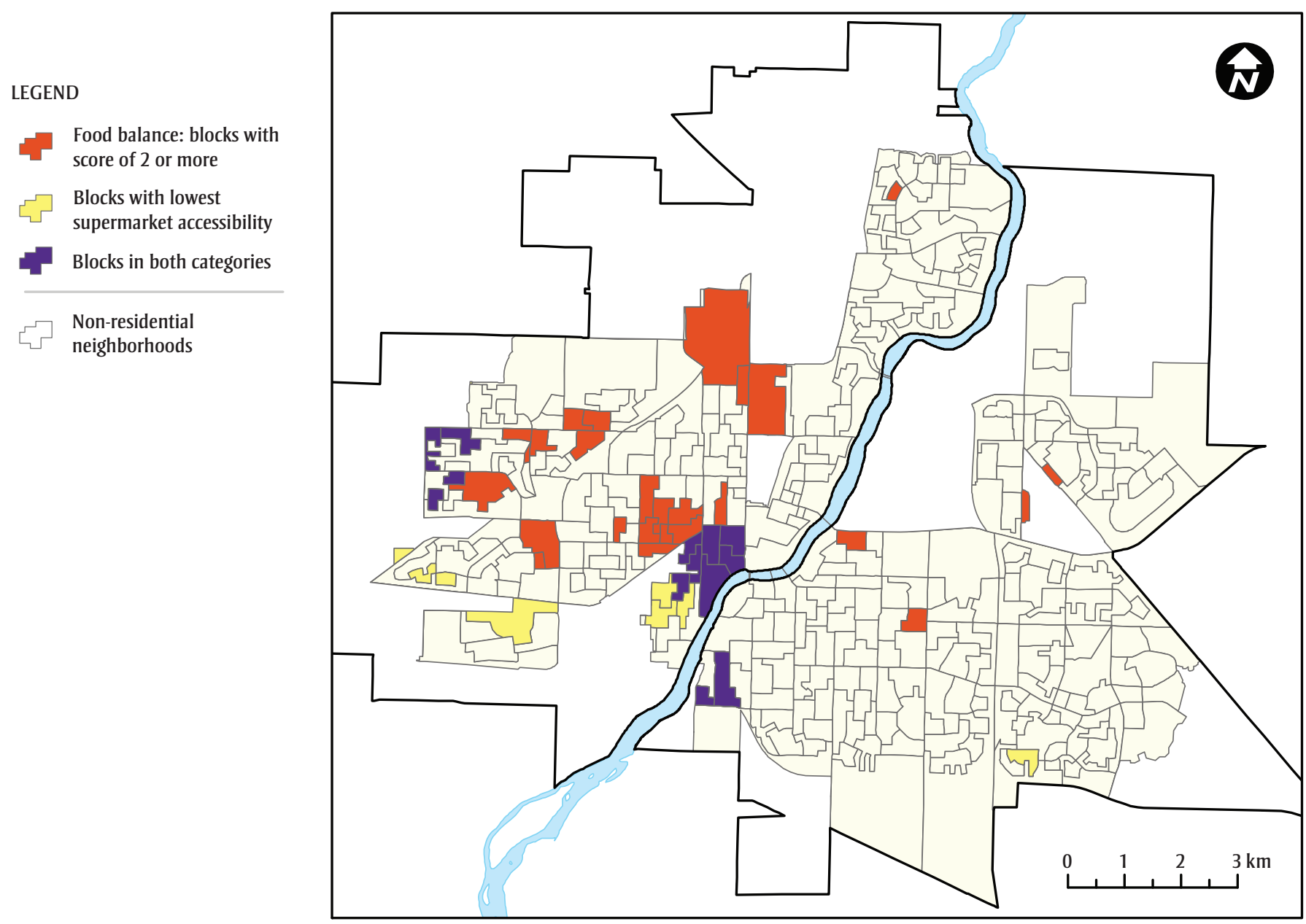

Areas of concern shifted according to whether social deprivation or material deprivation was considered. Previous studies have almost exclusively considered the relationship between food access and material deprivation. However, it is entirely plausible that social deprivation is a separate and distinct construct and requires further study. Individual-level studies should be pursued to determine the precise pathways by which material and social deprivation at an area level affect food access and ultimately health behaviours. In other words, how does access and area-level deprivation affect what type of food is purchased and consumed? Health and place research needs to begin to account more fully for the mechanisms between place-based con- structs and individual health behaviours such as healthy food consumption. ${ }^{13,27}$

Our study is a unique contribution to the literature in terms of methodology: the majority of food access studies have used only one measure of access, ${ }^{14,46,47}$ and some have used more than one measure of access, ${ }^{7,48}$ but very few have combined an accessibility score and a food balance score. ${ }^{23}$ Our food balance score was similar to the Retail Food Environment Index used in a study in Edmonton, Alberta, that measured the number of fast food retailers plus the number of convenience stores divided by the number of grocery stores and specialty food stores all within a given radius. ${ }^{29}$ If we had used the Retail Food Environment Index in the Saskatoon con- text, it is likely that food imbalance scores would have been even higher because convenience stores far outnumber specialty food stores in Saskatoon.

Another unique contribution of our study was the use of a deprivation index that covers both material and social dimensions. As noted earlier, food access has been primarily studied in relation to material deprivation, and the implications of social deprivation have been understudied. Since the INSPQ deprivation index has been used to assess health status and outcomes in major metropolitan areas in Canada, ${ }^{49}$ our methodology could be easily applied to other Canadian cities to facilitate cross-jurisdictional comparisons, if national cut-offs are used (we used local cut-offs in this study). 
FIGURE 9

Socially deprived areas with poor supermarket accessibility and poor food balance, Saskatoon, Saskatchewan

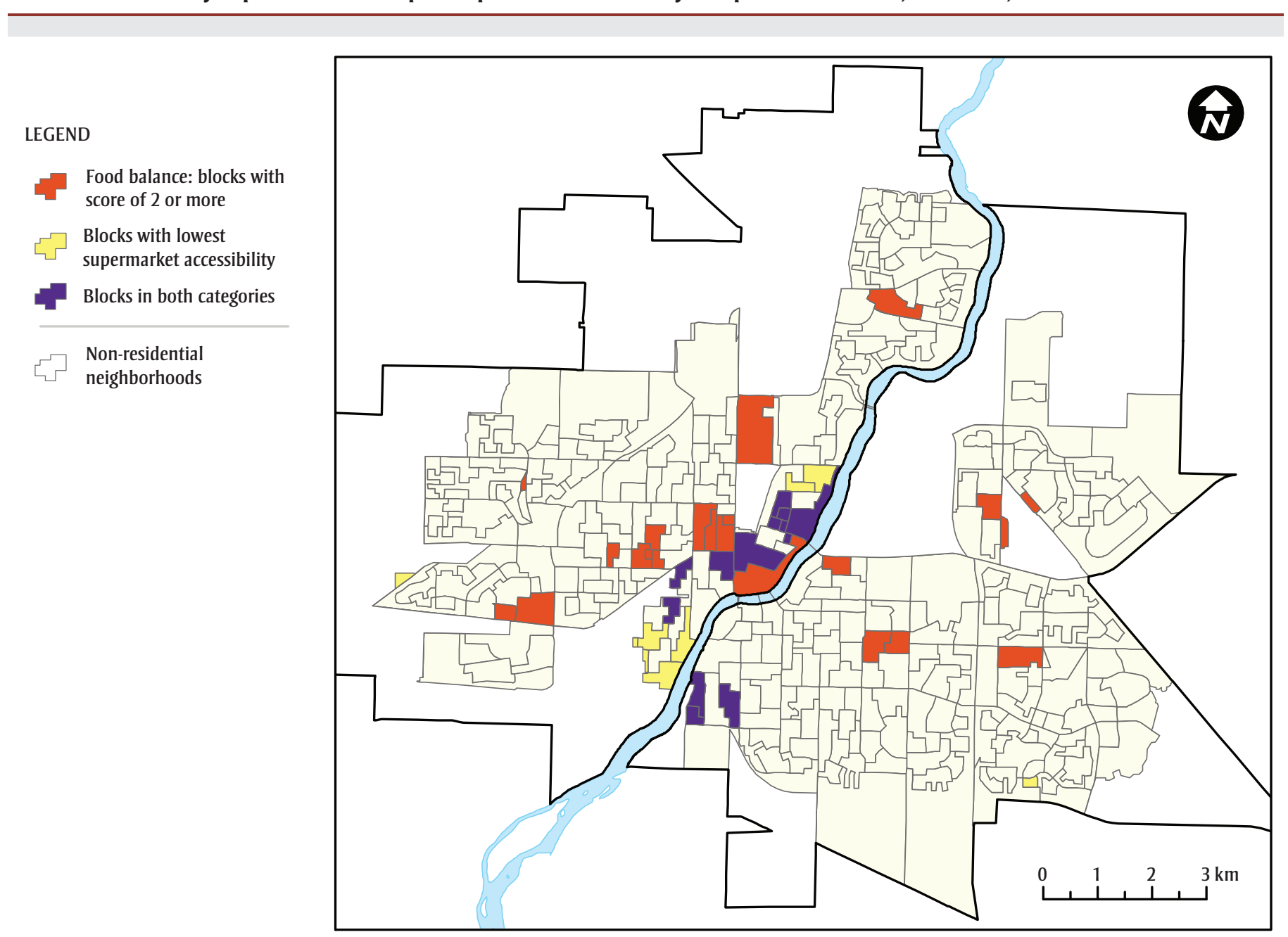

\section{Limitations}

While our study used innovative approaches to determine the associations between food access and food balance and deprivation, some limitations should be noted. First, while we considered many dimensions of access, our study did not account for economic access, for example, food prices being generally lower for unhealthier foods. ${ }^{50}$ Future studies should consider the interplay between access and food prices and how these are associated with both area-level deprivation and individual-level consumption patterns.

Our study also did not account for mobility. In other words, people do not always access food in the areas where they live. ${ }^{27}$ For instance, a recent study in Detroit, United States, found that individuals' activity spaces (i.e. the space where individuals conduct day-to-day activities) varied, often according to SES. ${ }^{51}$

Another limitation of our study was its ecological nature. Access at the area level does not guarantee that all individuals within that area are using the same food outlets or, more importantly, consuming the same food. As already noted, future studies should consider the interplay between area-level measures such as food access and individual-level measures such as food consumption patterns and health outcomes. Individual food consumption patterns would also shed light on whether individuals are selecting healthy options at supermarkets or unhealthy options at fast food outlets. This would be important to study since some fast food outlets are trying to market healthier options.

Our study did not account for trends over time. Even though some of our data was from different years (e.g. 2006-2008), this study was cross-sectional. Similar studies have also been almost entirely crosssectional, yet the relationship between environment and health is inherently temporal. $^{52}$ Longitudinal studies should be considered as a further innovation in this area of research, with access measured and mapped over time.

Finally, future studies should expand the inclusion criteria for food outlets. We did 
not include smaller and independent supermarkets in this analysis because they tend to be more expensive and stock less of a variety than do larger supermarkets. However, in certain areas they may be the nearest source of healthy foods. In addition, even though we included convenience stores that sell hot food, all convenience stores could be included in future studies given results from other studies. For example, an American study found that the greater the number of convenience stores in an area, the greater the probability of higher body mass indexes. ${ }^{53}$ Other studies have also included restaurants other than fast food outlets. $^{6}$

Although there were limitations, this study does suggest that policy and program interventions are required to improve food access in the city, particularly in deprived areas west of the South Saskatchewan River. One such intervention that should address the areas of concern found in this study is the Station 20 West community centre situated southwest of the South Saskatchewan River. The centre will include a not-for-profit grocery store that stocks affordable, healthy food. Other interventions that could be considered include the following: including quality food retail outlets as part of the planning criteria for every new neighborhood developed in the city; ${ }^{54}$ offering taxation incentives for the provision of food services in disadvantaged areas; ${ }^{54}$ developing neighborhood produce markets; ${ }^{54}$ encouraging urban agriculture ${ }^{55}$ and providing specialized transportation services to supermarkets or delivery programs from supermarkets. ${ }^{9,10}$ Evaluation of interventions is a key area that requires further exploration; although numerous interventions dealing with food access and balance in Canada have been proposed, there has been little research on the implementation and effectiveness of these interventions. ${ }^{29}$

\section{Conclusion}

Our study found that food access and balance varied according to material and social deprivation in Saskatoon. Some food access measures seemed to follow a socio-economic gradient (e.g. proximity to supermarkets according to material deprivation; food balance worsened as material and social deprivation increased). However, other measures of access did not follow a clear pattern. These results highlight the importance of contextual studies of food access since different patterns have emerged between and within countries and cities. This study also highlighted a number of other issues that should be explored in the Saskatoon context, such as individual-level food consumption patterns, mobility, temporal dimensions of food access and economic access.

\section{References}

1. Glanz K, Sallis JF, Saelens B, Frank LD. Nutrition Environment Measures Survey in stores (NEMS-S): development and evaluation. Am J Prev Med. 2007;32(4):282-9.

2. Rundle A, Neckerman KM, Freeman L, et al. Neighborhood food environment and walkability predict obesity in New York City. Environ Health Perspect. 2009;117(3):442-7.

3. Lovasi GS, Hutson MA, Guerra M, Neckerman KM. Built environments and obesity in disadvantaged populations. Epidemiol Rev. 2009;31:7-20.

4. Giskes K, van Lenthe F, Avendano-Pabon $\mathrm{M}$, Brug J. A systematic review of environmental factors and obesogenic dietary intakes among adults: are we getting closer to understanding obesogenic environments? Obes Rev. 2011;12:e95-106.

5. Charreire H, Casey R, Salze P, et al. Measuring the food environment using geographical information systems: a methodological review. Public Health Nutr. 2010;13(11):1773-85.

6. Larson NI, Story MT, Nelson MC. Neighbourhood environments: disparities in access to health foods in the U.S. Am J Prev Med. 2009;36(1):74-81.

7. Apparicio P, Cloutier MS, Shearmur R. The case of Montreal's missing food deserts: evaluation of accessibility to food supermarkets. Int J Health Geogr. 2007;6:4.
8. Burns $\mathrm{CM}$, Inglis $\mathrm{AD}$. Measuring food access in Melbourne: access to healthy and fast foods by car, bus and foot in an urban municipality in Melbourne. Health Place. 2007;13:877-85.

9. Cassady D, Mohan V. Doing well by doing good? A supermarket shuttle feasibility study. J Nutr Educ Behav. 2004;36:67-70.

10. Smoyer-Tomic KE, Spence JC, Armhein C. Food deserts in the prairies? Supermarket accessibility and neighbourhood need in Edmonton, Canada. Prof Geogr. 2006;58(3):307-26.

11. Chung C, Myers S. Do the poor pay more for food? An analysis of grocery store availability and food price disparities. J Consum Aff. 1999;33(2):276-96.

12. Black JL, Carpiano RM, Fleming S, Lauster N. Exploring the distribution of food stores in British Columbia: associations with neighbourhood socio-demographic factors and urban form. Health Place. 2011;17:96170 .

13. Walker RE, Keane CR, Burke JG. Disparities and access to healthy food in the United States: a review of food deserts literature. Health Place. 2010;16:876-84.

14. Morland K, Wing S, Diez Roux A. The contextual effect of the local food environment on residents' diets: the atherosclerosis risk in communities study. Am J Public Health. 2002;92(11):1761-7.

15. Odoms-Young AM, Zenk S, Mason M. Measuring food availability and access in African-American communities: implications for intervention and policy. Am J Prev Med. 2009:36(4 Suppl):S145-50.

16. Sallis JF, Glanz K. Physical activity and food environments: solutions to the obesity epidemic. Milbank Q. 2009;87(1):123-54.

17. Zenk SN, Lachance LL, Schulz AJ, Mentz G, Kannan S, Ridella W. Neighborhood retail food environment and fruit and vegetable intake in a multiethnic urban population. Am J Health Promot. 2009;23(4):255-64. 
18. Moore LV, Diez Roux AV, Nettleton JA, Jacobs DR Jr. Associations of the local food environment with diet quality-a comparison of assessments based on surveys and geographic information systems: the multiethnic study of atherosclerosis. Am J Epidemiol. 2008;167(8):917-24.

19. Diez Roux AV, Mair C. Neighborhoods and health. Ann N Y Acad Sci. 2010;1186:12545 .

20. Black J, Macinko J. Neighborhoods and obesity. Nutrition Rev. 2008;66(1):2-20.

21. Davis B, Carpenter C. Proximity of fast-food restaurants to schools and adolescent obesity. Am J Public Health. 2009;99(3):50510.

22. Maddock J. The relationship between obesity and the prevalence of fast food restaurants: state-level analysis. Am J Health Promot. 2004;19(2):137-43.

23. Mari Gallagher Research and Consulting Group. Good food: examining the impact of food deserts on public health in Chicago. Chicago (IL): Mari Gallagher Research and Consulting Group; 2006.

24. Hemphill E, Raine K, Spence J, SmoyerTomic KE. Exploring obesogenic food environments in Edmonton, Canada: the association between socioeconomic factors and fast food outlets. Am J Health Promot. 2008;22(6):426-32.

25. Powell LM, Auld MC, Chaloupka FJ, O’Malley PM, Johnston LD. Access to fast food and food prices: relationship with fruit and vegetable consumption and overweight among adolescents. Adv Health Econ Health Serv Res. 2006;17:23-48.

26. Sturm R, Datar A. Body mass index in elementary school children, metropolitan area food prices and food outlet density. Public Health. 2005;119:1059-68.

27. Feng J, Glass TA, Curriero FC, Stewart WF, Schwartz BS. The built environment and obesity: a systematic review of the epidemiologic evidence. Health Place. 2010;16:175-90.

28. Mari Gallagher Research \& Consulting Group. Examining the impact of food deserts on public health in Detroit. Chicago (IL): Mari Gallagher Research \& Consulting; 2007.
29. Spence JC, Cutumisu N, Edwards J, Raine KD, Smoyer-Tomic K. Relation between local food environments and obesity among adults. BMC Public Health. 2009;9:192.

30. Power EM. Determinants of healthy eating among low-income Canadians. Can J Public Health. 2005;96:S37-42.

31. Smith DM, Cummins S, Taylor M, et al. Neighbourhood food environment and area deprivation: spatial accessibility to grocery stores selling fresh fruit and vegetables in urban and rural settings. Int J Epidemiol. 2010;39(1):277-84.

32. Winkler E, Turrell G, Patterson C. Does living in a disadvantaged area mean fewer opportunities to purchase fresh fruit and vegetables in the area? Findings from the Brisbane food study. Health Place. 2006;12:306-19.

33. Woods F. Access to food in Saskatoon's core neighborhood. Saskatoon (SK): Community-University Institute for Social Research; 2003.

34. Beaulac J, Kristjansson E, Cummins S. A systematic review of food deserts, 19662007. Prev Chronic Dis. 2009;6(3): 1-10.

35. Cummins S, Macintyre S. The location of food stores in urban areas: a case study in Glasgow. Brit Food J. 1999;101(7):545-53.

36. Economic Research Service. Overview: food desert locator [Internet]. (ERS), U.S. Department of Agriculture (USDA) [updated 2012 Jul 6; cited 2012 Nov 5]. Available from: http://www.ers.usda.gov/ data-products/food-desert-locator.aspx

37. Smoyer-Tomic K, Spence J, Raine K, et al. The association between neighborhood socioeconomic status and exposure to supermarkets and fast food outlets. Health Place. 2008;14:740-54.

38. Block J, Scribner R, DeSalvo K. Fast food, race/ethnicity, and income: a geographic analysis. Am J Prev Med. 2004;27(3): 2117.

39. Pearce J, Blakely T, Witten K, Bartie P. Neighborhood deprivation and access to fast-food retailing: a national study. Am J Prev Med. 2007;32(5):375-82.
40. Fleischhacker SE, Evenson KR, Rodriguez DA, Ammerman AS. A systematic review of fast food access studies. Obes Rev. 2011;12:e460-71.

41. Larsen K, Gilliland J. Mapping the evolution of 'food deserts' in a Canadian city: supermarket accessibility in London, Ontario, 1961-2005. Int J Health Geogr. 2008;7:16.

42. Kaufman P, Lutz S. Competing forces affect food prices for low income households. Food Rev. 1997;20(2);8-12.

43. Austin SB, Melly SJ, Sanchez BN, Patel A, Buka S, Gortmaker SL. Clustering of fastfood restaurants around schools: a novel application of spatial statistics to the study of food environments. Am J Public Health. 2005;95(9):1575-81.

44. Pampalon R, Hamel D, Gamache P, Raymond G. A deprivation index for health planning in Canada. Chronic Dis Can. 2009;29 (4):178-91.

45. Statistics Canada. Dissemination area reference maps, reference guide: Census year 2006. Ottawa (ON): Statistics Canada; 2007. [Statistics Canada, Catalogue No.: 92-145GIE].

46. Cummins S, Macintyre S. The location of food stores in urban areas: a case study of Glasgow. Brit Food J. 1999;101(7):545-53.

47. Zenk SN, Schulz AJ, Israel BA, James SA, Bao S, Wilson ML. Neighborhood racial composition, neighborhood poverty, and the spatial accessibility of supermarkets in metropolitan Detroit. Am J Public Health. 2005;95(4):660-7.

48. Sharkey JR, Horel S, Han D, Huber JC. Association between neighbourhood need and spatial access to food stores and fast food restaurants in neighborhoods of Colonias. Int J Health Geogr. 2009;8(9): S151-5.

49. Canadian Population Health Initiative. Reducing gaps in health: socio-economic status in urban Canada. Ottawa (ON): CIHI; 2008.

50. Drewnowski A, Darmon N. Food choices and diet costs: an economic analysis. J Nutr. 2005;135(4):900-4. 
51. Zenk SN, Schulz AJ, Matthews, SA, et al. Activity space environment and dietary and physical activity behaviours: a pilot study. Health Place. 2011;17:1150-61.

52. Cummins S, Macintyre S. Food environments and obesity-neighbourhood or nation? Int J Epidemiol. 2006;34:100-4.

53. Powell LM, Auld MC, Chaloupka FJ, O’Malley PM, Johnston LD. Associations between access to food stores and adolescent body mass index. Am J Prev Med. 2007;33 (4 Suppl): S301-7.

54. Toronto Food Policy Council. Food retail access and food security for Toronto's lowincome citizens. Toronto (ON): Food Policy Council; 1996. Discussion paper series no.7. $32 \mathrm{p}$.

55. Desjardins E, Lubczynski J, Xuereb M. Incorporating policies for a healthy food system into land use planning: the case of Waterloo Region, Canada. JAFSCD. 2011;2(1):127-40 